Revista de la red interuniversitaria de estudios sobre las literaturas rioplatenses contemporáneas en Francia

\title{
El mudo que habla
}

Maximiliano Crespi

\section{OpenEdition \\ Journals}

Edición electrónica

URL: http://journals.openedition.org/lirico/1211

DOI: $10.4000 /$ lirico. 1211

ISSN: 2262-8339

Editor

Réseau interuniversitaire d'étude des littératures contemporaines du Río de la Plata

\section{Referencia electrónica}

Maximiliano Crespi, «El mudo que habla », Cuadernos LIRICO [En línea], 9 | 2013, Publicado el 01

septiembre 2013, consultado el 22 septiembre 2020. URL : http://journals.openedition.org/lirico/1211 ; DOI : https://doi.org/10.4000/lirico.1211

Este documento fue generado automáticamente el 22 septiembre 2020

\section{(c) (i) (9)}

Cuadernos LIRICO está distribuido bajo una Licencia Creative Commons Atribución-NoComercialSinDerivar 4.0 Internacional. 


\section{El mudo que habla}

Maximiliano Crespi

\section{REFERENCIA}

Erlan, Diego, El amor nos destrozará, Buenos Aires, Tusquets, 2012, 260 págs. 
"Casi no quedan Pedros en este Páramo", solía responder David Viñas desde una mesa del bar La Paz cada vez que se le interrogaba por la literatura de los noventa. La ironía hacía evidente referencia a una generación de escritores sin proyecto intelectual. Pero cuando la insistencia del interrogador solicitaba nombres, un ademán tajante cortaba de cuajo el humo y la frivolidad policial para ir al grano: "Nadie se pregunta qué, por qué ni para quién escribe antes de mostrar los dientes para la solapa". El abandono de la célebre tríada sartreana venía a confirmar la resignación de ese momento de libertad en que una práctica específica se articula sobre un proyecto político. Viñas intuía que lo que se resignaba era, más que una moral, una responsabilidad concreta: la de optar

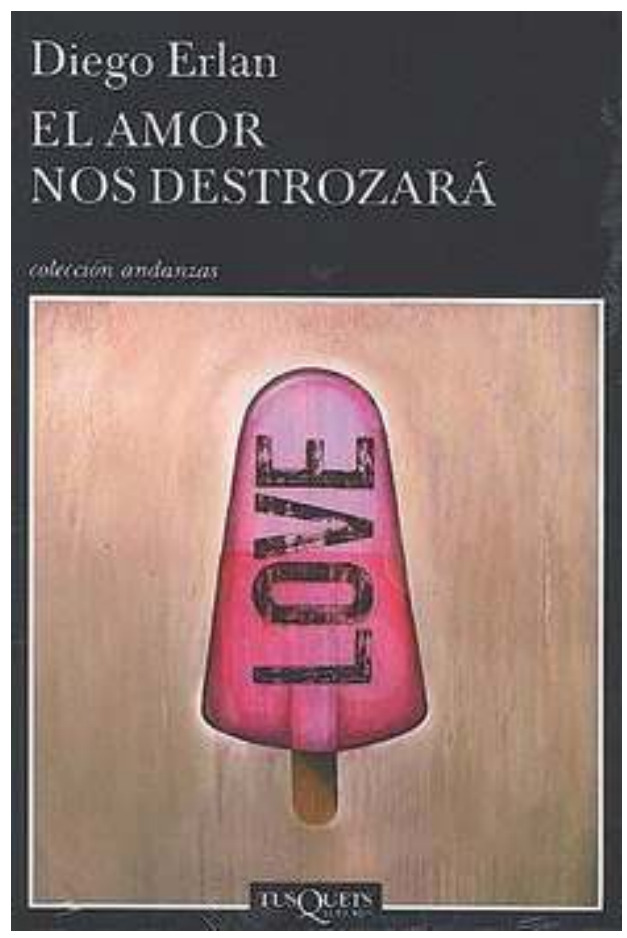
entre hacer literatura con valor asertivo, sea sosteniendo y reafirmando los valores conservadores de la sociedad burguesa, sea -al contrario-, cuestionándolos, confrontándolos y contribuyendo a su gradual descomposición; o hacer literatura con valor interrogativo, transformando la propia ficción en el signo de esa opacidad histórica que se vive como subjetividad.

2 Con una extraña novela de iniciación que contradice casi todas las convenciones del género, Diego Erlan asume el meritorio gesto de inscribirse en esa última tendencia, al emplazar su literatura en esa zona ciega donde se graban sintomáticamente las cuitas de la alienación contemporánea. Con todo, vale la pena repetir lo obvio : las intenciones sólo son suficientes cuando son malas. El amor nos destrozará es un comienzo. Y su primer gesto interrogativo se afirma en la determinación de convertir ese mismo comienzo en un relato neurótico, que insiste, a la vez, en ir en busca de un (otro) comienzo perdido, acaso irrecuperable. Erlan lo intuye : lo que se graba en la pérdida es, a la larga, trauma. Es por eso que elige fundar el comienzo de su ficción en la grieta abierta por un duelo no realizado. Es una determinación perversa : hacer girar el relato alrededor de una bolsa negra que promete poco más que una regresión patológica. Sobre esa compleja perversión se articulan a la vez la fábula y la ficción.

3 La trama de la novela es de apariencia sencilla. Agustín tiene siete años y está de vacaciones en la casa de su abuela. En ese contexto tiene lugar un primer acontecimiento: la muerte -inexplicable en su perspectiva- de su hermana casi adolescente. Después de eso, gradualmente, su vida deriva en un tránsito lánguido, progresivo y resignado del abandono a la soledad, y de ésta al aislamiento, como acompañando el manto de silencio que cubre ese acontecimiento traumático que con el tiempo acaba por arruinar el universo familiar. El descubrimiento de una bolsa negra con casetes grabados por su hermana traza un nuevo punto de inflexión en el relato y en la vida del personaje (el del comienzo de su adolescencia). A partir de allí, se desarrolla el resto la novela de aprendizaje que tiene por trasfondo implícito los años 
noventa. Pero ni la fábula ni la ficción se resumen en ella. Es más : una y otra confabulan incluso contra la lógica progresiva que pauta la convención genérica.

Mientras la fábula trabaja deliberadamente con la huida y el retorno, la ficción se desperdiga en una dialéctica inmóvil. La página inicial redunda casi al señalar la no pertenencia del relato a sus voces. ${ }^{1}$ La trama se arruga y produce la no-identificación de la persona narrativa a un único estado y a un solo punto de vista. $Y$ ese procedimiento encauza la ficción en un régimen (deliberadamente) delirado. La anomalía trastorna la lógica progresiva e inscribe el relato en el régimen mismo de la perturbación. Una poética de la regresión licua además toda posibilidad de delimitación precisa entre la escena del relato y la escena de lo relatado. Tal fluctuación frustra los emplazamientos a partir de una frase que abre de un solo tajo las tres dimensiones del relato : espacio, persona y tiempo. "Quiere acordarse" y "Quiero acordarme" son las frases que agrietan sendas dimensiones y desencadenan, en esas dos palabras -ni antes ni después-, una ficción en que el personaje es otro y el mismo, el tiempo es pasado y presente, y el lugar se encuentra siempre desplazado de su sitio. En cualquier caso, el narrador está siempre en otra parte. Llega a la escena y se apropia de la primera persona que a su vez se apropia de su función. El que "quiere acordarse" es el que no puede evitar acordarse. $\mathrm{Y}$ en ese movimiento hay un riesgo que la novela de Erlan no siempre resuelve con precisión. En el flujo vertiginoso de esos pasajes los tiempos y los espacios se acortan abruptamente (a veces en una sola frase que hace de puente) y la escena del relato no termina de abandonar la mirada del niño ni de materializar la distancia de la rememoración. En ese punto el narrador, como ocurre con frecuencia en Formas de volver a casa (2011) de Alejandro Zambra (novela a la que Erlan ha considerado en alguna oportunidad de las más representativas de su generación), aparece superpuesto de manera tal que da lugar a una doble contaminación (que eventualmente afecta el verosímil realista en que se apoya el relato) : en ciertos momentos, el narrador-niño aparece exhibiendo sorprendentes rasgos de madurez; en otros, la perspectiva del narrador-adolescente aparece preñada de infantilismos. Pero, en contrapartida de esos momentos de evidente desliz, hay un acierto claro y contundente. El que "quiere acordarse" crea, en el revés de esa simple frase, una nueva dimensión en la ficción. El que quiere acordarse no es el chico que cierra los ojos ni es el adolescente que busca un sentido en una grabación de Joy Division repetida mecánicamente, como un mantra. Es otro, el que se tapa los oídos, el que se satura de ruido para negarse la escucha (no es casual que, como el propio Erlan ha declarado públicamente, el título inicial de esta novela fuera precisamente Ruido): es el monstruo que se crea y recrea sobre una infancia condensada en el trauma y una adolescencia signada por el desastre.

La inexplicada muerte de la hermana (por la que late sin dudas la sombra de un deseo incestuoso) durante unas vacaciones en La Pampa funciona, al comienzo, como el tabú que empuja el relato sin que la expectativa policial llegue a imponerse al Bildungsroman malogrado que la novela busca narrar. El cambio de espacios (de la casa de La Maruja al departamento en Buenos Aires) dispone una nueva retórica vital, pero los efectos de lo silenciado corroen gradualmente las funciones estructurales de la familia pequeñoburguesa. El adolescente que trata de hacer pie en esa rutina de degradación hereda de sus padres -vieja costumbre de las clases medias- ante todo los traumas, los miedos y los tabúes. En consecuencia, la alienación marca de manera definitiva las relaciones sociales, sus experiencias y las condiciones mismas de su aprendizaje afectivo, intelectual, amoroso o sexual -sea que éstas se produzcan en su casa, en la terraza de su edificio, en la escuela, en la casa de Alonso (su único amigo). En un 
contexto signado por la degradación, Agustín es incapaz de rebelarse porque no se reconoce en su propia voluntad. No ve en los otros más que extraños, seres reducidos a la humillación y a la miseria ; pero no es capaz de verse él mismo como un extranjero, puesto que su propia libertad ha sido reducida al nudo de coacciones que asuelan la escena presente y que no cesan de remitir a un pasado velado en la infancia. La alienación es la única experiencia real que es capaz de incorporar. Su percepción del mundo está siempre mutilada : presenta los rasgos mudos de una ruptura del contacto afectivo con la realidad, una incapacidad concreta para entablar relaciones de consonancia con el medio, una indiferencia afectiva ante las reacciones, una ruptura de los lazos de socialización efectiva y una significativa retirada que absorbe toda resistencia hasta convertirlo en una suerte de artilugio apático e indolente.

6 No es casual que la fábula prescinda de toda mueca histórica o sociológica (intencionadamente borrada en la novela). Al contrario: esa borradura es un signo determinante a la hora de comprender la manera en que esta literatura elabora su condición política. La novela familiar no se cierra en lo literal ; dice más de lo que dice, pero lo dice de manera alusiva. El relato de Erlan convoca lo alegórico ; y es lo alegórico lo que se vuelve praxis política al demandar del lector no una actitud pasiva sino una determinación activa en la reposición del contexto implícito. Menemato, clase media, alienación. La tríada no es fortuita. Sirve para ir encuadrando, como diría Viñas, exasperada y dramáticamente el texto en su contexto ; pero también para empezar a raspar el texto y ver los momentos en que literalidad y alegoría se conciben -en una productiva dialéctica- la una por la otra o, como bien ha escrito Juan Bautista Ritvo, la una en la otra. El personaje y la novela familiar de Erlan plantean un estado de situación. Y comprometen un horizonte generacional en tanto trabajan (con desesperación) sobre lo reprimido. Las regresiones a la infancia -que sólo una mirada superficial podría reducir a simples flashbacks lúdicos- son un efecto que vuelve a la causa sólo por desvíos. El narrador que habita y produce discursivamente esa historia es incapaz de separar los personajes porque es incapaz de instaurar entre el presente y el pasado un límite infranqueable. No encuentra manera de asumir la pérdida porque no puede objetivar su sentido en una causa. Es por ello que no sólo experimenta sus relaciones con los otros como ajenas, sino que además sustrae sistemáticamente -tanto del relato como de la escena relatada- las percepciones de su propio cuerpo. ${ }^{2}$

7 Erlan presenta una novela familiar en la que todos son hablados a través de su propio silencio. Pone al lector ante una pequeña sociedad dañada que vive su cotidianeidad de una manera asfixiante, obstinada en no enfrentar la pérdida que marca su propia historia, aterrorizada ante la posibilidad de que se repita. Es una sociedad que, al no poder proyectar directamente su realidad -con sus conflictos y contradicciones-, la refleja de manera indirecta, a través de mitos que la excusan, la justifican y la idealizan en la mascarada narcisista de "lo pasado, pisado". Todo el relato está mediado. Más que el narrador, quienes narran son las películas y las músicas. Es por eso que las fijaciones y regresiones se multiplican casi tanto como las desidentificaciones : lo imposible no es reconocerse en el "yo" sino liquidar el pasado y asimilarlo al contenido actual de la experiencia desde la que ese "yo" se reconoce. La metáfora insectil, a la que el relato apela en reiteradas ocasiones, avanza también en esa dirección. La pérdida está siempre ligada a los insectos (hormigas, moscas, abejas, cucarachas). Los insectos saben, hacen el trabajo: se devoran el cadáver de su hermana hasta que de él sólo quedan esos huesos que no guardan otra memoria que la que atestigua su silencio. Es la imaginación la que pone en escena la vena alegórica de un relato de formación malograda. A medida 
que ese relato crece (porque no se puede decir que avance) queda al descubierto que en la base de esa frustración está sin dudas la sombra de un conflicto real que la pequeña sociedad pretende conjurar desde el silencio. El silencio es cura y es prevención. Por eso es el rictus determinante en la educación de un niño en que la pequeña sociedad sobreimprime sus propios miedos, sus miserias y sus culpas. La determinación pedagógica es bastante alusiva ("No tenía que preguntar qué había pasado" (97) y el peso de lo silenciado puede vislumbrase en la frase que el padre se repite una y otra vez hasta que opta por dejar de hablar ("-Algún día le voy a pedir perdón a tu hermana." [42]). El silencio es aquí el signo de una experiencia arruinada por la pérdida. Es el vacío que lo arrolla todo: "La suposición convierte a unos casetes sin etiqueta en un pozo ciego. No puede verse un carajo. El pozo es profundo y hay silencio. Y el silencio es ruido. Y más allá del silencio está el pasillo y la oscuridad y el recuerdo de una mano perdida en el parqué sucio de una habitación, de una casa, de una vida que ya no está" (107). El silencio es el síntoma -esto es, el avatar de la verdad de la novela. Es también la negación a la escucha con que el padre resigna su función y su lugar ("me pidió que no le contara nunca más las cosas que pasaban en casa mientras él no estaba, que en algún momento él no iba a estar más y yo tendría que decidir qué hacer" [171]). Y es el rasgo con que el protagonista acepta ser caracterizado ("-Entonces tiene que llamarse Mudo -dijo Simón. Me gustaba el nombre" [161]).

8 Entre la sordera y la mudez el silencio se sobreimprime como un fenómeno de pasaje que hace de la disfunción un procedimiento de desdoblamiento y desidentificación entre el personaje y el narrador. Como el fusilado que vive, y a diferencia del canario mudo en Rodolfo Walsh y Gardel (2008) de David Viñas, el narrador es "el mudo que habla" (es decir, su escucha). Es el que sortea las desidentificaciones, el que cruza los tiempos, los espacios y las formas y estados de imaginación (el recuerdo, el sueño, el delirio, la interpretación y el testimonio). Es el que, desde su condición heterotópica, da sutil equilibrio al relato de lo inconsistente. Uno de los mayores aciertos narrativos de Erlan está precisamente en la sutileza con que teje esos pasajes.

Otro, por demás notable, radica en su decisión de tramar la propia estructura de la novela de acuerdo al Bildungsroman traumático que viene a relatar. El libro está deliberada y progresivamente construido según la estructura de un hormiguero. Es un conjunto monticular complejo de túneles, pasajes y conductos producidos en la tierra suelta que cubre la superficie de otro conjunto, más complejo e intrincado, que se extiende de manera subterránea. La metáfora se justifica en una progresión ética: tierra es la patria y la patria es la lengua.

Abordar el aprendizaje como una sucesión de frustraciones, fracasos y fobias es una elección deliberada que podemos imaginar del lado de Roberto Arlt y contra Miguel Cané. Narrarla -con belleza pero también con crueldad- haciendo pie en las miserias y canalladas de gran parte de una generación acobardada y arrinconada por fantasmas propios y heredados es un desafío que tiene sus riesgos. Y casi no hay margen de error cuando de lo que se habla es también del Bildungsroman traumático de la generación que lee -o que está eventualmente en posibilidad de leer-su propio rostro desfigurado.

11 Que la trama misma de El amor nos destrozará cruce lateralmente, en silencio, esa simulación de fin de la historia que fue el menemato, no es poco sintomático : supone una inversión activa de la tecnología política que se impuso en esa época como una abierta proliferación mediática de las imágenes y los discursos que conducía al sinsentido : esa época en la que todo -pero absolutamente todo- podía ser dicho ¿no fue 
a la vez la de mayor gravitación del silencio ? Que la trama se desencadene sobre los restos de memoria de personajes -hay que sostener ese plural esquizo- que rehúyen y conjuran el relato de la pérdida, tampoco es menor. La pregunta incómoda pero oportuna que hay que hacer es qué viene a decir la novela de Erlan sobre este punto luego de El ignorante de Juan Terranova (2004), libro cuyos virulentos y polémicos enunciados el tibio progresismo contemporáneo ha optado por ningunear : ¿será que, como parecen venir a confirmarlo textos como Varadero y Habana maravillosa (2009) de Hernán Vanoli o Can solar (2012) de Carlos Godoy -por completo ajenos a la extorsión temática que asume la desaparición en la imaginación literaria de autores como Martín Kohan, por ejemplo-, la literatura supone siempre una interrogación signada por la pérdida? ¿Será ella misma siempre el saldo de una mutilación que la antecede ? ¿Será que en ella coinciden, perversa y silenciosamente, la sutura y el conjuro?

Más aún : que la novela de Erlan atente contra la ilusión de un personaje que en vez de constituirse se descompone y que lo convierta finalmente en un centro falso (donde las progresiones y las regresiones le impiden establecer incluso, tal como reza el viejo adagio althusseriano, una relación imaginaria con sus propias condiciones de existencia) porque el centro real de esa escena desfondada es justamente una ausencia, ¿no señala -de manera oblicua pero también problemática- la alienación que se acentúa en el fetichismo de la subjetividad que las "literaturas del yo" exhiben como una virtud? Finalmente, que su autor decida comprometer a la vez la estructura del relato en el signo reflejo de una gradual descomposición del argumento, y que asuma la impregnación de su propia escritura de ese ruido/silencio que borra la escucha cuando borra (enmudece) al propio sujeto de la enunciación, ¿no da cuenta, a la vez, de la radicalidad de su intervención y de su apuesta en favor de una concepción del lector como productor? Es probable; aunque son hipótesis que se irán descartando o ratificando con la publicación de sus próximos trabajos. En cualquier caso, cabe por ahora subrayar el gesto : a Erlan no le tiembla el pulso.

\section{NOTAS}

1. Vale la pena citar aquí in extenso la página inicial de la novela para percibir en ella, no sólo los desdoblamientos y pasajes de personas pronominales, sino también los desplazamientos del punto de vista narrativo que serán una constante procedimental a lo largo del relato :

"La historia no empieza así.

$\mathrm{Ni}$ con gritos ni con llantos ni siquiera cuando la madre le pregunta cómo es el rostro de una mosquita muerta.

Quiere acordarse.

El chico cierra los ojos, cierra la boca, hace fuerza para recordar algo pero no lo consigue.

Y la historia no empieza.

Sabe que tampoco empieza con la imagen del padre que deja de hablar y la del chico que se esconde en el placard y encuentra una bolsa con tres casetes grabados de la hermana.

El chico, entonces, quiere acordarse de un día de carnaval en el pueblo de La Maruja, de la mano de Greta aferrada a la suya, de aquel largo pasillo en la casa de su abuela. 
Quiere acordarse.

Porque la historia empieza el día en que mi hermana murió." (9).

2. Como bien apunta el sociólogo José Taurel Xifra, el cuerpo puede ser efectivamente un índice de lectura (uno de entre los muchos posibles) porque "permite abordar el problema de la alienación en las sociedades modernas (y también las posmodernas)". Específicamente, porque "el cuerpo es el soporte último (o primero) de la realidad"; en tanto "se compone de tres dimensiones, y la alienación se verifica tanto en la escisión entre cada una de estas dimensiones como también al interior de cada una. Así, el cuerpo individual aparece aislado, no se tiene pleno control sobre su experiencia, y además sus fuerzas se reencuentran como un poder ajeno a pesar de ser lo más irreductiblemente propio. La primera dimensión es el 'cuerpo subjetivo' del hombre, es decir su propia corporalidad, esa porción de materia orgánica finita donde se asienta el yo. La segunda, incumbe al 'cuerpo objetivo' o 'cuerpo inorgánico', es decir a la extensión natural, al entorno sin cuyo intercambio la vida sería imposible, hablamos de la naturaleza. El tercer momento corresponde al cuerpo colectivo que conforma una sociedad al trabajar en conjunto, al cooperar. Aquí la categoría de cuerpo aparece envestida en una concepción de totalidad, y además es la realización de los momentos anteriores ya que la dialéctica los conserva" ("La dialéctica del cuerpo", en M. Crespi, M. Lagarrigue y J. Taurel Xifra (comps.), Marx manuscrito. Ideología, humanismo y alienación, Buenos Aires, 17 grises editora, 2013, p. 90-91).

\section{AUTORES}

\section{MAXIMILIANO CRESPI}

Universidad Nacional de La Plata 